\title{
DESEMPENHO DE UMA SEMEADORA-ADUBADORA DIRETA, EM FUNÇÃO DA VELOCIDADE DE DESLOCAMENTO E DO TIPO DE MANEJO DA BIOMASSA DA CULTURA DE COBERTURA DO SOLO ${ }^{1}$
}

\author{
KLINGER B. BRANQUINHO ${ }^{2}$, CARLOS E. A. FURLANI ${ }^{3}$, AFONSO LOPES ${ }^{3}$, \\ ROUVERSON P. da SILVA ${ }^{3}$, DANILO C.C. GROTTA ${ }^{2}$, EDINAN A. BORSATTO ${ }^{2}$
}

\begin{abstract}
RESUMO: O objetivo do presente trabalho foi estudar o desempenho de uma semeadora-adubadora, operando em duas velocidades sobre a palhada da cultura do milheto (Pennisetum glaucum (L.) R. Brown), após diferentes manejos, na semeadura direta da cultura da soja (Glycine Max L.). O experimento foi realizado com seis tratamentos, em esquema fatorial, delineados em blocos ao acaso, com quatro repetições. Os tratamentos combinaram três manejos (triturador de palhas tratorizado, rolo-

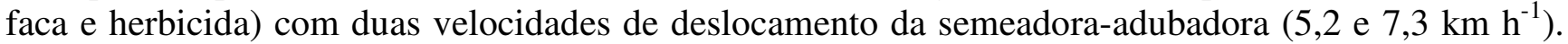
Foram analisadas as seguintes variáveis: acúmulo e decomposição de massa seca do milheto, índice de emergência da cultura da soja, uniformidade de distribuição longitudinal de sementes, capacidade de campo efetiva da semeadora-adubadora e produtividade da soja. Os resultados mostraram que não houve diferença na decomposição da massa de milheto após os manejos e que esses, juntamente com a velocidade de deslocamento do conjunto trator-semeadora-adubadora, não influenciaram no número de dias para a emergência das plântulas de soja e na distribuição longitudinal das sementes. A capacidade de campo efetiva da semeadora-adubadora foi maior na velocidade mais alta. O rendimento de grãos não diferiu significativamente nos tratamentos estudados.
\end{abstract}

PALAVRAS-CHAVE: distribuição longitudinal, velocidade de decomposição, plantio direto.

\section{PERFORMANCE OF A SEEDING-FERTILIZER MACHINE IN FUNCTION OF THE DISPLACEMENT SPEED AND SOIL COVER CROP BIOMASS MANAGEMENT}

SUMMARY: The objective of the present work was to evaluate three different managements of the Pennisetum glaucum (L.) R. Brown crop and two-speed displacement in a no-tillage system of soybean (Glycine max L.) crop on a typical Eutrophic Red Latosol. The experiment was arranged in six treatments, in a factorial array, in a randomized complete block design, with four replications. The treatments were constituted from three combination of crop managements (straw chopper, residue coulter and herbicide) and two speed displacement of the seeding-fertilizer machine (5.2 and $7.3 \mathrm{~km} \mathrm{~h}^{-1}$ ). The following variables have been analyzed: emergency index of the soybean, longitudinal seeding uniformity (evaluated by the percentage of acceptable spacings), double distribution and distribution failure, and operational capacity of the seeding-fertilizer machine. There was no difference on the mass decomposition of the Pennisetum crop after management. The management of the Pennisetum crop and the displacement of the seeding-fertilizer machine did not influence the number of days for soybean crop emergency and the longitudinal distribution of the seeds. The operational capacity of the seeding-fertilizer machine was higher at the faster speed. The crop yield did not differ on the studied treatments.

KEYWORDS: longitudinal distribution, speed decomposition, no-tillage.

\footnotetext{
${ }^{1}$ Trabalho financiado pela Fapesp, processo ${ }^{\circ}$ 01/03977-8

${ }^{2}$ Eng $^{\mathrm{o}}$. Agro ${ }^{\mathrm{o}}$, Mestrando em Ciência do Solo, Faculdade de Ciências Agrárias e Veterinárias, UNESP, Câmpus de Jaboticabal - SP.

${ }^{3}$ Prof. Dr., Departamento de Engenharia Rural, Faculdade de Ciências Agrárias e Veterinárias, UNESP, Câmpus de Jaboticabal - SP.

Recebido pelo Conselho Editorial em: 13-5-2003

Aprovado pelo Conselho Editorial em: 9-3-2004
} 


\section{INTRODUÇÃO}

O sistema de semeadura direta consiste na técnica de implantar uma cultura em solo não preparado previamente, diferenciando-se dos outros processos de semeadura pela menor intensidade de mobilização do solo e pela cobertura do solo com restos vegetais das culturas anteriores. Aliado a isso, existe a necessidade da rotação de culturas, que é uma prática simples, empregada desde a antigüidade, trazendo grandes benefícios para o agricultor. O sistema de semeadura direta e a rotação de culturas promovem, juntos, inúmeras vantagens, dentre as quais se podem destacar: menor necessidade de água de chuvas para iniciar o plantio, economia de combustível, aumento da atividade biológica do solo em função do aumento do teor de matéria orgânica e menor perda por erosão. $\mathrm{O}$ manejo de culturas de cobertura pode ser feito de várias maneiras, dentre as quais se podem citar: a) mecânico, com triturador de palhas tratorizado, roçadora e rolo-faca, e b) químico, com herbicidas; cada um desses manejos deixa a vegetação sobre a superfície do solo de diferentes formas, acarretando decomposição diferenciada aos resíduos vegetais.

O plantio direto (termo mais comum) na agricultura mecanizada é definido como um sistema de semeadura, no qual a semente é depositada diretamente em solo não preparado. Os resíduos vegetais da cultura anterior permanecem na superfície do solo, e as plantas daninhas são controladas com o uso de herbicidas. Fundamenta-se na substituição gradativa de processos mecânico-químicos por processos biológico-culturais de manejo do solo e na maior eficiência econômica decorrente da redução de gastos com insumos, energia e controle da erosão (DERPSCH et al., 1991).

CALEGARI (1990) cita que, para compor um sistema de rotação de culturas, é fundamental a escolha das plantas de cobertura do solo e adubação verde. Entretanto, a escolha dessas plantas, considerando-se a melhor época de semeadura da cultura comercial, tem sido o grande entrave para o êxito do sistema; pela falta de informações, o uso das espécies ainda não está sendo efetuado de forma compatível quanto ao clima e solo, afirmam GREGO et al. (2001).

Existe a possibilidade de reduzir o uso de herbicidas nas culturas de verão, como milho, soja e feijão, quando semeadas em sistema de plantio direto após culturas de cobertura do solo que apresentam lenta decomposição e ação alelopática (ALMEIDA, 1985).

O milheto (Pennisetum glaucum (L) R. Brawn) é uma cultura utilizada no sistema plantio direto para a formação de palhada, podendo ser utilizado também na rotação lavoura-pecuária e ainda para rotação com culturas comerciais, como o caso da soja. O milheto é capaz de acumular grande quantidade de nutrientes, sendo em alguns casos superiores ao milho, segundo relatos de NORMAN et al. (1995).

Nas culturas implantadas com a finalidade de cobertura do solo, adubação verde e mesmo as produtoras de grãos com alta produção de biomassa na parte aérea, torna-se, por vezes, necessário um manejo especial para fracionar, reposicionar e/ou colocar o material em contato com a superfície do solo. Essa operação está diretamente relacionada ao tipo de preparo do solo que está sendo realizado e aos mecanismos sulcadores das semeadoras-adubadoras (LEVIEN et al., 1998). DERPSCH et al. (1991) relatam que existem diversos métodos de manejo de resíduos vegetais, tais como o emprego de roçadora, rolo-faca, segadora, herbicidas dessecantes e triturador de palhas tratorizado.

A soja é uma das culturas que melhor se adaptam ao sistema plantio direto, segundo LANDERS (1995), e os rendimentos dessa, ao se considerar o efeito médio de várias safras, equivalem aos diferentes sistemas de manejo do solo, com pequena vantagem para o plantio direto.

DELAFOSSE (1986) relata que a velocidade na operação de semeadura é um dos parâmetros que mais influencia no desempenho de semeadoras, sendo a distribuição longitudinal de sementes no sulco de semeadura afetada pela velocidade de deslocamento, que, por sua vez, influencia na produtividade da cultura. Entretanto, SILVA (2000) conclui que a uniformidade de distribuição de 
sementes não foi influenciada pela velocidade de deslocamento na implantação de culturas de milho e soja. KLEIN et al. (2002) apresentam resultados semelhantes e afirmam que o aumento de velocidade não afetou o porcentual de espaçamentos duplos e falhos nem a produtividade.

O objetivo do presente trabalho foi verificar o desempenho de uma semeadora-adubadora de precisão, trabalhando em duas velocidades de deslocamento sobre a palhada da cultura do milheto manejado de três formas.

\section{MATERIAL E MÉTODOS}

O experimento foi instalado na Faculdade de Ciências Agrárias e Veterinárias da UNESP, Câmpus de Jaboticabal - SP, localizado nas coordenadas geográficas $21^{\circ} 15$ '22" latitude sul e 48 $18^{\circ}$ '58" longitude oeste, com altitude média de $570 \mathrm{~m}$, apresentando clima Cwa (subtropical), de acordo com classificação de Köeppen.

O solo da área experimental é classificado pela EMBRAPA (1999) como Latossolo Vermelho Eutroférrico típico, textura muito argilosa, A moderado, caulinítico vítreo.

O experimento foi realizado com duas velocidades de deslocamento do conjunto trator-

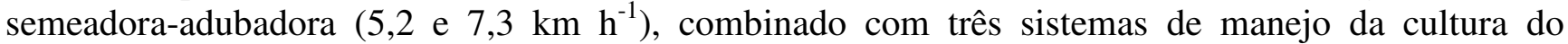
milheto (triturador de palhas tratorizado, rolo-faca e herbicida glyphosate com $4 \mathrm{~L} \mathrm{ha}^{-1}$ ) na semeadura da cultura da soja. O delineamento experimental foi o de blocos inteiramente casualizados, em esquema fatorial $(2 \times 3)$, totalizando seis tratamentos, com quatro repetições. A semeadura do milheto ocorreu no dia 16-3-2001, no final da estação chuvosa na região, no ano agrícola de 2000-2001. Foram coletadas amostras de massa verde, seca em estufa para determinar a quantidade de matéria seca acumulada aos 30; 60 e 90 dias após a semeadura e no dia do manejo realizado aos 150 dias após a semeadura da cultura do milheto. Aos 20; 44; 78 e 108 dias após o manejo, retiraram-se amostras para a determinação da matéria seca remanescente por hectare para observar a decomposição da mesma. A semeadura da soja foi realizada no dia 31-10-2001.

Os equipamentos utilizados foram: trator MF 620 de 77,2 kW (105 cv) 4 x 2 TDA, trator MF 285 de $62,5 \mathrm{~kW}(85 \mathrm{cv})$, trator MF 5275 de 55,2 kW (75 cv); semeadora-adubadora de fluxo contínuo, marca Semeato TD 200 de arrasto com 15 linhas espaçadas de 0,20 m, com sulcadores de discos duplos para sementes e fertilizantes, utilizada na semeadura do milheto; semeadora-adubadora de precisão montada, marca Vence-Tudo, modelo SA 11500, com cinco linhas espaçadas de 0,45 m, disco de corte de palha, sulcador tipo haste para adubo, disco duplo defasado para semente, com massa de $1.110 \mathrm{~kg}$, utilizada para a semeadura da soja; triturador de restos culturais marca Jan/Tritton 2300, montado, largura de corte de 2,3 m e massa de $735 \mathrm{~kg}$; rolo-faca simples com 13 facas dispostas em sua periferia, largura de corte de $2,10 \mathrm{~m}$ e massa com lastro de $720 \mathrm{~kg}$, e pulverizador jacto PJ 600 , barra de $9 \mathrm{~m}$, equipada com 18 bicos tipo leque para aplicação de herbicidas, com massa de $195 \mathrm{~kg}$.

As variáveis avaliadas foram: acúmulo e decomposição de massa seca do milheto, índice de emergência da cultura da soja, uniformidade de distribuição longitudinal de sementes que foi avaliada pela porcentagem de espaçamentos aceitáveis, distribuição dupla e falha na distribuição, capacidade de campo efetiva da semeadora-adubadora e produtividade da cultura da soja.

$\mathrm{O}$ acúmulo e a decomposição da massa seca foram analisados por meio da coleta das massas com quadrado de ferro de $0,5 \mathrm{~m}$ de lado e a posterior secagem do material em estufa a $70{ }^{\circ} \mathrm{C}$, por $48 \mathrm{~h}$; em seguida, realizou-se a pesagem e converteu-se o valor obtido para quilograma de matéria seca por hectare.

A avaliação do índice de emergência das plântulas de soja foi determinada por meio de contagens diárias e calculada de acordo com a equação de EDMOND \& DRAPALA (1958). 
Na avaliação da distribuição longitudinal, a distância entre as plântulas foi medida com régua graduada em mm. A porcentagem de espaçamentos aceitáveis foi obtida de acordo com as normas da ABNT, citadas por KURACHI et al. (1989), considerando-se como aceitáveis os espaçamentos situados entre 0,5 a $1,5 \mathrm{vez}$ o espaçamento médio esperado; abaixo do limite inferior, foi admitido como sementes duplas e, acima do limite superior do intervalo, considerou-se como falha na distribuição. A capacidade de campo efetiva da semeadora-adubadora foi determinada segundo MIALHE (1974), com auxílio de cronômetro digital e de uma trena.

A produtividade foi determinada colhendo-se as plantas em $4 \mathrm{~m}$ de cinco linhas centrais da parcela, totalizando $9 \mathrm{~m}^{2}$. Foram realizadas a pesagem dos grãos e a determinação do teor de água, expressando-se a produtividade com teor de água de $13 \%$.

Os dados foram submetidos à análise de variância e, quando o valor do teste $\mathrm{F}$ foi significativo a $5 \%$ de probabilidade, foi realizado o teste de Tukey, para a comparação de médias.

\section{RESULTADOS E DISCUSSÃO}

Na Figura 1, apresenta-se a evolução da massa seca da cultura do milheto aos 30; 60 e 90 dias após a semeadura e no dia do manejo (150 dias após semeadura). Observa-se que houve incremento da massa seca até os 90 dias após a semeadura; porém, no dia do manejo, a massa seca apresentou um decréscimo em relação à última amostragem, isso devido à entrada na fase de senescência da cultura. Durante o período em que a cultura permaneceu no campo, ocorreu uma precipitação média mensal de $46 \mathrm{~mm}$.

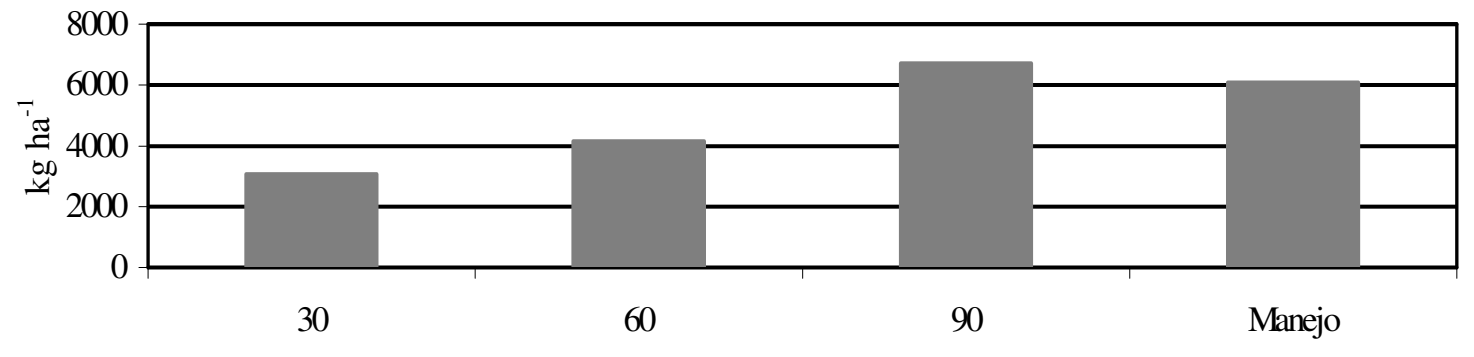

Dias

FIGURA 1. Acúmulo de massa seca da cultura do milheto aos 30; 60 e 90 dias após a semeadura e no dia do manejo (150 dias após semeadura).

Na Figura 2, apresentam-se os valores da massa seca do milheto e de plantas daninhas aos 20; 44; 78 e 108 dias após os manejos. Nos manejos com rolo-faca e triturador de palhas, houve acréscimo da massa seca dos 20 aos 78 dias, devido à emergência de plantas daninhas, rebrota e sementeira do milheto; o decréscimo apresentado aos 108 dias decorrente da dessecação em área total aos 63 dias após o manejo e semeadura da cultura da soja. No manejo com herbicida, ocorreu uma diminuição da massa dos 20 para os 44 dias em função da morte fisiológica das plantas de milheto e daninhas; o aumento apresentado aos 78 dias é relativo ao surgimento de plantas daninhas (principalmente de folhas largas) e a diminuição de massa aos 108 dias é também função da dessecação em área total e semeadura da soja.

Os manejos não diferiram estatisticamente entre si quanto à decomposição de massa nos períodos estudados. 


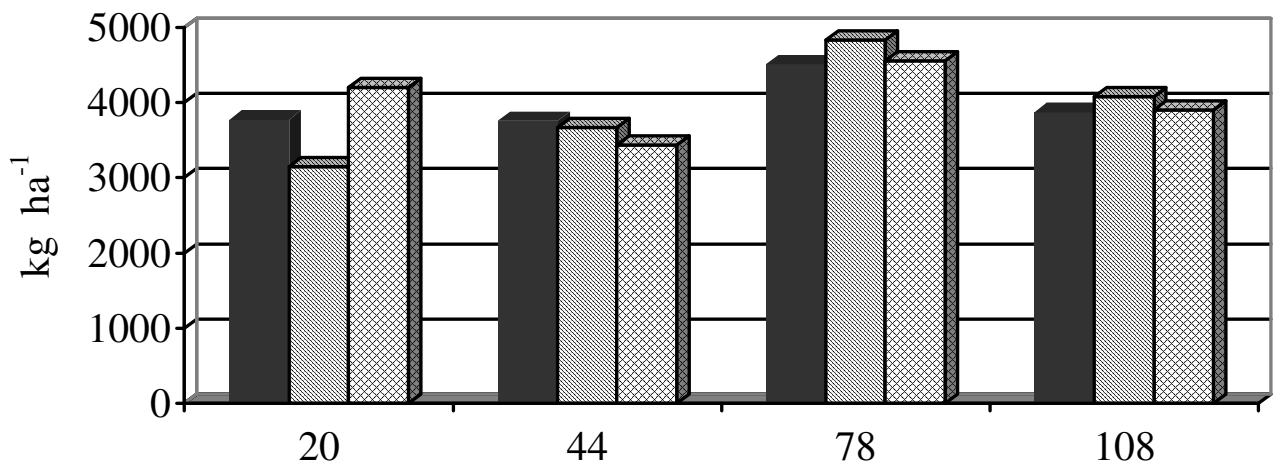

Dias

\section{Rolo-Faca $\square$ Triturador 图 Herbicida}

FIGURA 2. Massa seca do milheto e de plantas daninhas aos 20; 44; 78 e 108 dias após os manejos.

A distribuição longitudinal de sementes, apresentada na Tabela 1, não apresentou diferença significativa entre os tratamentos. Porém, nota-se que os espaçamentos aceitáveis possuem média de $44,8 \%$, os falhos $23,1 \%$ e os múltiplos $32,1 \%$; isso se assemelha aos dados de KLEIN et al. (2002) e demonstra que menos da metade das sementes foram depositadas com espaçamentos adequados.

TABELA 1. Distribuição longitudinal de sementes, espaçamentos aceitáveis, espaçamentos falhos e espaçamentos múltiplos $(\%)$.

\begin{tabular}{lccc}
\hline \multicolumn{1}{c}{ Fator } & $\begin{array}{c}\text { Espaçamentos Aceitáveis } \\
(\%)\end{array}$ & $\begin{array}{c}\text { Espaçamentos } \\
\text { Falhos (\%) }\end{array}$ & $\begin{array}{c}\text { Espaçamentos } \\
\text { Múltiplos }(\%)\end{array}$ \\
\hline Manejo (M $)$ & & & \\
\hline Rolo-faca & 43,7 & 23,8 & 32,4 \\
Triturador & 44,0 & 22,7 & 33,4 \\
Herbicida & 43,3 & 22,9 & 30,4 \\
\hline Velocidade $\mathrm{km} \mathrm{h}^{-1}(\mathrm{~V})$ & & & 31,6 \\
\hline V1: 5,2 & 45,3 & 23,1 & 32,5 \\
V2: 7,3 & 44,3 & 23,1 & $0,3351 \mathrm{~ns}$ \\
\hline M & $0,3416 \mathrm{~ns}$ & $0,0980 \mathrm{~ns}$ & $0,1009 \mathrm{~ns}$ \\
\hline V & $0,0938 \mathrm{~ns}$ & $0,0001 \mathrm{~ns}$ & $1,2584 \mathrm{~ns}$ \\
\hline M C.V. $(\%)$ & $0,7473 \mathrm{~ns}$ & $0,8861 \mathrm{~ns}$ & 23,0 \\
\hline
\end{tabular}

O número médio de dias para a emergência das plântulas de soja (Tabela 2) não foi afetado pelos manejos efetuados na cultura do milheto e pela variação da velocidade de deslocamento do conjunto trator semeadora-adubadora, sendo em média de 9,8 dias.

Em relação à produtividade, os resultados não apresentaram diferenças significativas entre os tratamentos. Isso evidencia que o aumento de velocidade pode resultar em maior capacidade de campo efetiva sem prejudicar a produtividade da cultura da soja, concordando com os relatos de KLEIN et al. (2002). 
TABELA 2. Número de dias para a emergência das plântulas de soja e produtividade.

\begin{tabular}{lcc}
\hline \multicolumn{1}{c}{ Fator } & Dias para Emergência & Produtividade $\left(\mathrm{kg} \mathrm{ha}^{-1}\right)$ \\
\hline Manejo ( M ) & & 3.503 \\
\hline Rolo-faca & 9,7 & 3.469 \\
Triturador & 10,1 & 3.716 \\
Herbicida & 9,6 & \\
\hline Velocidade $\mathrm{km} \mathrm{h}^{-1}(\mathrm{~V})$ & & 3.574 \\
\hline V1: 5,2 & 9,7 & 3.552 \\
V2: 7,3 & 9,8 & $0,9563 \mathrm{~ns}$ \\
\hline $\mathrm{M}$ & $2,0620 \mathrm{~ns}$ & $0,0180 \mathrm{~ns}$ \\
\hline $\mathrm{V}$ & $0,1715 \mathrm{~ns}$ & $0,1908 \mathrm{~ns}$ \\
\hline M x V & $0,0679 \mathrm{~ns}$ & 10,9 \\
\hline
\end{tabular}

Como era de se esperar, a capacidade de campo efetiva da operação de semeadura e adubação foi influenciada pela velocidade de deslocamento do conjunto, sendo maior na velocidade mais alta. Os diferentes manejos realizados na cultura do milheto não influenciaram na capacidade operacional.

TABELA 3. Capacidade de campo efetiva na semeadora-adubadora (ha $\mathrm{h}^{-1}$ ).

\begin{tabular}{lcccc}
\hline Velocidade $\left(\mathrm{km} \mathrm{h}^{-1}\right)$ & \multicolumn{3}{c}{ Manejos } & \multirow{2}{*}{ Média } \\
\cline { 2 - 4 } & Rolo-Faca & Triturador & Herbicida & $1,15 \mathrm{~b}$ \\
\hline 5,2 & 1,15 & 1,16 & 1,15 & $1,65 \mathrm{a}$ \\
7,3 & 1,64 & 1,63 & 1,67 & \\
\hline Média & $1,40 \mathrm{~A}$ & $1,40 \mathrm{~A}$ & $1,41 \mathrm{~A}$ & \\
\hline
\end{tabular}

C.V. $=1,7 \%$ DMS manejo $=0,03$ DMS velocidade $=0,02$

\section{CONCLUSÕES}

A velocidade de decomposição da massa de milheto não é influenciada pelos diferentes manejos estudados.

Os manejos na cultura do milheto e a velocidade de deslocamento do conjunto trator semeadoraadubadora não influenciaram no número médio de dias para a emergência das plântulas da cultura da soja, na distribuição longitudinal de sementes e na produtividade da soja.

\section{AGRADECIMENTOS}

À Fundação de Amparo à Pesquisa do Estado de São Paulo (FAPESP), pelo apoio financeiro ao trabalho.

\section{REFERÊNCIAS BIBLIOGRÁFICAS}

ALMEIDA, F.S. Atualização em plantio direto. Campinas: Fundação Cargill, 1985. 343 p.

CALEGARI, A. Plantas para adubação verde de inverno no sudoeste do Paraná. Boletim Técnico Instituto Agronômico do Paraná, Londrina, n.35, p.1-36, 1990.

DELAFOSSE, R.M. Máquinas sembradoras de grano gruesso. Santiago: FAO, 1986. 48 p.

DERPSCH, R.; ROTH, C.H.; SIDIRAS, N.; KOPKE, U. Controle da erosão no Paraná, Brasil: sistemas de cobertura do solo, plantio direto e preparo conservacionista. Eschborn: GTZ, 1991. 272 p. 
EDMOND, J.B.; DRAPALA, W.L. The effects of temperature, sand and soil acetone on germination of okra seed. Proceedings of the American Society for Horticutural Science, Alexandria, v.71, p.42834, 1958.

EMPRESA BRASILEIRA DE PESQUISA AGROPECUÁRIA. Centro Nacional de Pesquisa de Solos. Sistema brasileiro de classificação de solos. Brasília, 1999. 412 p.

GREGO, C.R.; BENEZ, S.H.; COSTA, A.M.; MARQUES, J.P.; MAHL, D.; SILVA, A.R.B.; PONTES, J.R.V.; LEITE, M.A.S.; OLIVEIRA, M.F.B.; SALVADOR, A. Disponibilidade hídrica e produção de cobertura vegetal na região central do Estado de São Paulo. In: CONGRESSO BRASILEIRO DE ENGENHARIA AGRÍCOLA, 30., 2001, Foz do Iguaçu. Anais... Foz do Iguaçu: Sociedade Brasileira de Engenharia Agrícola, 2001. 1 CD ROM.

KLEIN, V.A.; SIOTA, T.A.; ANESI, A.L.; BARBOSA, R. Efeito da velocidade na semeadura direta de soja. Engenharia Agrícola, Jaboticabal, v.22, n.1, p.75-82, jan. 2002.

KURACHI, S.A.H.; COSTA, J.A.S.; BERNARDI, J.A.; COELHO, J.L.; SILVEIRA, G.M. Avaliação tecnológica de semeadoras e/ou adubadoras: tratamento de dados de ensaios e regularidade de distribuição de sementes. Bragantia, Campinas, v.48, n.2, p.249-62, 1989.

LANDERS, J.N. Fascículo de experiências de plantio direto no cerrado. Goiânia: APDC, 1995. $261 \mathrm{p}$.

LEVIEN, R.; FURLANI, C.E.A.; SIQUEIRA, R.; GAMERO, C.A. Desempenho de um triturador de palhas tratorizado em resíduos culturais de milho. In: CONGRESO LATINOAMERICANO DE INGENIERÍA RURAL, 2., 1998, La Plata. Anais... La Plata, Argentina: UNLP, 1998. 1 CD ROM.

MIALHE, L. G. Manual de mecanização agrícola. São Paulo: Agronômica Ceres, 1974. 301 p.

NORMAN, M.J.T.; ROSSIELLO, C.J.; SEARLE, P.G.E. The ecology of tropical food crops. 2. ed. Cambridge: University Press, 1995. 430 p.

SILVA, S.L. Avaliação de semeadoras para plantio direto: demanda energética, distribuição longitudinal e profundidade de deposição de sementes em diferentes velocidades de deslocamento. 2000. 123 f. Tese (Doutorado em Energia na Agricultura) - Faculdade de Ciências Agronômicas, Universidade Estadual Paulista, Botucatu, 2000. 